\title{
Management of upper gastrointestinal bleeding
}

\author{
I Govender,' S Rangiah, ${ }^{2}$ HI Okonta ${ }^{3}$ \\ ${ }^{1}$ Department of Family Medicine, Kalafong Hospital and University of Pretoria, South Africa \\ ${ }^{2}$ Department of Family Medicine, University of KwaZulu-Natal, South Africa \\ ${ }^{3}$ Department of Family Medicine, Sefako Makgatho Health Sciences University, South Africa \\ Corresponding author, email: indiran.govender@gmail.com
}

This paper will describe the common symptoms, signs and causes of upper gastrointestinal bleeding. We will then provide advice on the management of upper gastrointestinal bleeding at primary care level.

\section{Introduction}

Upper gastrointestinal bleeding (UGIB) is a common and lifethreatening emergency. ${ }^{1,2}$ In any given population, the incidence of UGIB can range from 50 to 150 per 100000 adults per year with a mortality rate between $2.5 \%$ and $15 \% .^{1,3,4}$ Elderly patients are more prone to UGIB and there is a higher incidence in males. ${ }^{2,4}$

UGIB is defined as significant bleeding from the gastrointestinal tract proximal to the Ligament of Treitz, ${ }^{5,6}$ the anatomical landmark located between the proximal two thirds and the distal one third of the duodenum. The oesophagus, stomach and duodenum have a rich vascular supply, ${ }^{7}$ shown in Figure 1, and, if compromised, can result in life-threatening haemorrhage.

\section{Causes}

Acute UGIB is classified into two broad categories viz non-variceal and variceal, with the former being more common and including oesophagitis, oesophageal ulcers, oesophageal cancer, MalloryWeis tear, gastritis, gastric ulcer, gastric cancer, Dieulafoy's lesion, vascular ectasias (angiodysplasia), duodenal ulcer, aorto-enteric fistula, haemobilia and haemosuccus pancreaticus. ${ }^{8}$

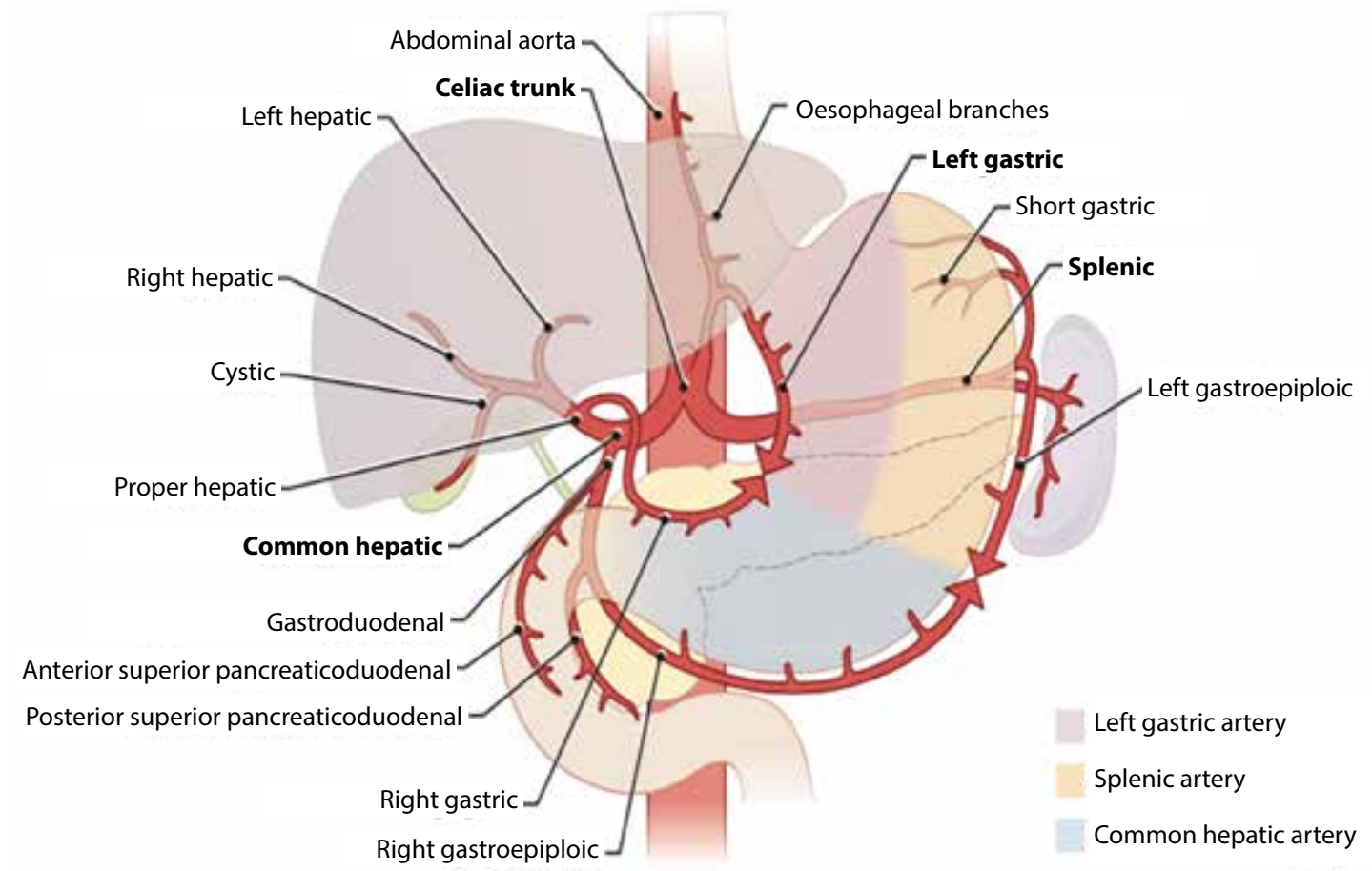

Figure 1. Arterial supply of the foregut ${ }^{7}$ 
The pathophysiology of non-variceal bleeding involves either arterial haemorrhage as in ulcers and mucosal deep tears, or low-pressure venous haemorrhage as seen in telangiectasis and angioectasis. ${ }^{2}$ Variceal causes, accounting for $10 \%$ of cases, include bleeding from gastric varices, oesophageal varices or portal hypertensive gastropathy. ${ }^{9,10}$ The underlying mechanism is thought to be raised portal pressure transmitted to oesophageal and gastric varices leading to portal gastropathy. ${ }^{2}$

Peptic ulcer disease is still the most common cause of UGIB and is significantly related to Helicobacter pylori infection. ${ }^{2}$ This organism disrupts the mucous barrier and has a direct inflammatory effect on gastric and duodenal mucosa. H. pylori colonises $>50 \%$ of the population, with $10-20 \%$ of colonised individuals becoming symptomatic and developing ulcers.

The goal of assessment (through appropriate history, physical examination, laboratory tests), is to determine the severity of the bleed, recognise potential sources of the bleed and search for conditions that may influence definitive management. ${ }^{11}$

\section{Clinical presentation}

Presenting complaints may include weakness, dizziness, nausea or dyspepsia. The presence of haematemesis localises bleeding to the foregut. Frank, red blood is an indication of moderate to severe ongoing bleeding while coffee-ground vomitus suggests a delayed bleed. Coffee-ground vomitus is formed by blood that has oxidised within the stomach and is darkened and thickened.

A large haemorrhage in the region of the foregut may manifest as haematochezia (red or maroon stool) with rapid transit of blood through the gastrointestinal tract usually associated with orthostatic hypotension. Melaena on the other hand, is black tarry stool suggestive of bleeding that originates proximal to the Ligament of Treitz. Those presenting with frank haematemesis tend to have more severe bleeding than those with just melaena. ${ }^{11}$

Recurrence of bleeding from the same lesion is common and a past medical history must be determined. In addition, a history of dyspepsia with nocturnal symptoms, early satiety, peptic ulcer disease, malignancy, angiodysplasia, nonsteroidal antiinflammatory drug use, and previous aortic surgery must be elicited.

Preexisting co-morbid conditions like coronary artery disease, pulmonary disease, renal failure, coagulopathies, thrombocytopaenia, hepatic dysfunction and dementia must be ascertained as these conditions may affect patient management.

\section{Physical examination}

Physical examination will determine the haemodynamic status of the patient. Significant examination findings of a tachycardia above 100 beats per minute, systolic blood pressure less than $90 \mathrm{mmHg}$, increased capillary refill time above two seconds and cold peripheries are early warning signs of decreased perfusion.

Determination of orthostatic hypotension indicates a blood loss of at least $20 \%$ of the blood volume. ${ }^{11}$

The patient must be examined for stigmata of chronic liver disease like spider angiomata, gynaecomastia, collateral abdominal veins, ascites and asterixis. The tell-tale abdominal and groin scars indicative of previous aortic surgery might point

Table I. Important points to consider in the history and examination of a patient with UGIB

\begin{tabular}{|c|c|c|}
\hline $\begin{array}{l}\text { Important points in history taking to assess } \\
\text { the site, severity and aetiology of UGIB }\end{array}$ & Examination must include & Investigations \\
\hline $\begin{array}{l}\text { General symptoms - fatigue, weakness, } \\
\text { dizziness, syncope }\end{array}$ & Determination of $A B C s$ & Full blood count \\
\hline $\begin{array}{l}\text { Localising symptoms - heartburn, epigastric } \\
\text { pain, diffuse abdominal pain }\end{array}$ & Vital signs and inspection for pallor & Urea and electrolytes \\
\hline $\begin{array}{l}\text { Weight loss, jaundice, dysphagia, retching } \\
\text { (Mallory-Weiss) }\end{array}$ & Blood pressure for orthostatic hypotension & Liver function tests \\
\hline $\begin{array}{l}\text { Specific bleeding manifestations - } \\
\text { haematemesis, malaena, haematochezia }\end{array}$ & $\begin{array}{l}\text { Inspection for abdominal and groin scars, and } \\
\text { palpation for abdominal tenderness }\end{array}$ & Coagulation studies \\
\hline Previous UGIB & $\begin{array}{l}\text { Search for skin manifestations - acanathosis } \\
\text { nigrans, vascular anomalies }\end{array}$ & $\begin{array}{l}\text { ECG and cardiac enzymes for patients with } \\
\text { ischaemic heart disease }\end{array}$ \\
\hline Peptic ulcer disease & $\begin{array}{l}\text { Search for oral manifestations - perioral } \\
\text { telangiectasia }\end{array}$ & May need to cross match blood \\
\hline Malignancy and radiation exposure & $\begin{array}{l}\text { Search for signs of chronic liver disease } \\
\text { (jaundice, ascites) }\end{array}$ & $\begin{array}{l}\text { Chest and abdominal radiography - to exclude } \\
\text { perforation or obstruction if associated pain }\end{array}$ \\
\hline $\begin{array}{l}\text { NSAID use, antiplatelet, anticoagulant, } \\
\text { bismuth, iron, tobacco and alcohol use }\end{array}$ & Nasogastric aspirate examination & $\begin{array}{l}\text { CT scan - liver disease, previous aortic surgery, } \\
\text { cholecystitis, pancreatitis }\end{array}$ \\
\hline $\begin{array}{l}\text { Vascular disease (previous aortic surgery) and a } \\
\text { history of trauma (haemobilia) }\end{array}$ & Rectal examination & $\begin{array}{l}\text { In referral centres angiography for a potential } \\
\text { source in cases of obscure source }\end{array}$ \\
\hline $\begin{array}{l}\text { Co-morbidities - coronary artery disease, } \\
\text { chronic obstructive pulmonary disease, } \\
\text { renal failure, liver disease (cirrhosis, portal } \\
\text { hypertension) }\end{array}$ & Stool examination & $\begin{array}{l}\text { Sengstaken Blakemore tube or temporary } \\
\text { oesophageal stent placement in } \\
\text { life-threatening variceal bleed }\end{array}$ \\
\hline
\end{tabular}

UGIB - upper gastrointestinal bleed, NSAID - nonsteroidal anti-inflammatory drug, ECG - electro-cardiography, CT - computed tomography 
to the presence of a herald bleed (aorta-enteric fistula) and urgent need for computed tomographic angiography (CTA).

Although nasogastric tube placement is controversial, a positive aspirate in the presence of haematochezia is suggestive of an upper gastrointestinal tract bleed. A negative aspirate on the other hand does not rule out upper gastrointestinal bleeding. Aspiration of red blood or coffee ground is predictive of an acute lesion or an inactive bleed respectively (Table I).

\section{Laboratory investigations}

The basic investigations that will determine and guide further management include a full blood count, urea and electrolytes, liver function tests and coagulation studies.

Normocytic red blood cells will suggest acute bleeding while a microcytic appearance or iron deficiency is indicative of chronic blood loss. A high urea to creatinine ratio is expected in cases of UGIB due to absorption as blood passes through the gastrointestinal tract, possibly exacerbated by decreased renal perfusion. ${ }^{12}$

\section{Risk stratification}

Risk scores utilising clinical factors and laboratory data are routinely used to predict adverse outcomes in UGIB. ${ }^{13}$ The Rockall score and the Glasgow-Blatchford score are the two widely used stratification tools that predict the likelihood of continuation of bleed or of re-bleeding and the risk of death..$^{14,15}$

The Glasgow-Blatchford score (0-23 points) does not consider endoscopic criteria and is useful in the emergency room. ${ }^{11}$ This scoring system helps in selecting which patients may benefit from outpatient endoscopy (Table II).

The Glasgow-Blatchford score seems to be superior to the preendoscopic Rockall score in all important clinical outcomes including mortality. The recently developed CANUKA score was found to be superior at identifying low-risk patients and performed similar in predicting re-bleeding, therapeutic intervention and mortality. ${ }^{14}$

\section{Emergency management}

The principles of management for all patients with UGIB are similar. Standard care should commence with ensuring that the airway is open and patent, breathing is adequate and that the circulatory system is adequate for perfusion. If there is an altered level of consciousness, the airway needs to be secured and protected. All patients should receive supplemental oxygen via a nasal canula. ${ }^{6}$

Intravenous peripheral access with two wide bore catheters must be obtained early, followed by immediate fluid resuscitation with crystalloids, either Ringers lactate or normal saline. Fluid balance must be strictly monitored following insertion of a Foleys catheter.

In the haemodynamically unstable patient, resuscitation should continue with packed red blood cells (RBCs). In patients with suspected variceal bleeding, caution must be taken against over transfusion as this can precipitate worsening of the bleeding. ${ }^{11}$

The goal of transfusion should be aimed at maintaining a haemoglobin level greater than $7 \mathrm{~g} / \mathrm{dL}$ except for patients with unstable coronary artery disease who are at risk for adverse events. In the setting of anaemia - the goal should be maintaining a haemoglobin level above $9 \mathrm{~g} / \mathrm{dL} .{ }^{11}$

Acid suppression with intravenous proton pump inhibitors is initiated and reviewed immediately after the source of bleeding is identified. The European Society of Gastroenterology (ESGE) recommends using high-dose PPIs given as a bolus (e.g. omeprazole $80 \mathrm{mg} \mathrm{IVI}$ ) and then running an infusion over 72 hours (e.g. omeprazole $8 \mathrm{mg} / \mathrm{hr}$ ). ${ }^{16}$ However, systemic review comparing intermittent versus continuous infusion therapy proved similar efficacy, thus therapy can be tailored for each patient. ${ }^{17,18}$

Intravenous erythromycin ( $3 \mathrm{mg} / \mathrm{kg}$ over $30 \mathrm{~min}$ ) if given one to two hours prior to endoscopy will improve visualisation and diagnostic and therapeutic yield at the time of endoscopy. Metoclopramide is an alternative prokinetic..11

Early upper endoscopy within 24 hours of patient presentation is the diagnostic modality of choice for UGIB. It is used to establish the bleeding site and also achieve haemostasis. Endoscopic modalities for achieving haemostasis include self-expandable metallic stents and endoscopic variceal ligation for oesophageal varices; cyanoacrylate injection for gastric varices; and endoscopic haemospray for nonvariceal UGIB. Interventional radiological techniques such as balloon-occluded retrograde transvenous obliteration and transjugular intrahepatic portosystemic shunting can be considered for gastric varices.

Table II. Glasgow-Blatchford score

\begin{tabular}{|c|c|c|c|c|c|c|c|c|}
\hline \multicolumn{2}{|c|}{ Systolic BP } & \multicolumn{2}{|c|}{ Blood urea (mmol/L) } & \multicolumn{3}{|c|}{ Haemoglobin (g/dL) } & \multicolumn{2}{|l|}{ Other features } \\
\hline 100-109 & 1 & $6.5-7.9$ & 2 & Male & Female & & Pulse $\geq 100$ & 1 \\
\hline 90-99 & 2 & $8.0-9.9$ & 3 & $12.0-12.9$ & $10.0-11.9$ & 1 & Melaena & 1 \\
\hline \multirow[t]{3}{*}{$<90$} & 3 & $10-24.9$ & 4 & $10.0-11.9$ & & 3 & Syncope & 2 \\
\hline & & $\geq 25$ & 6 & $<10$ & $<10$ & 6 & Liver disease & 2 \\
\hline & & & & & & & Cardiac failure & 2 \\
\hline
\end{tabular}




\section{Coagulopathy}

Managing coagulopathy in patients who are critically ill and presenting with UGIB is an essential component for haemostasis. National Institute for Health and Care Excellence (NICE) guidelines are listed in Box 1. If haemodynamically unstable, endoscopic intervention should be prioritised. No strong evidence yet supports the use of tranexamic acid. ${ }^{17}$

Box 1. NICE recommendations for managing coagulopathy in upper
gastrointestinal bleeding
- Do not offer platelet transfusion to patients who are not actively
bleeding and are haemodynamically stable
- Offer platelet transfusion to patients who are actively bleeding and
have a platelet count of less than $50 \times 109 / \mathrm{L}$
- Offer fresh frozen plasma to patients who have either a fibrinogen
level of less than $1 \mathrm{~g} / \mathrm{L}$ or a prothrombin time (INR) or activated
partialthromboplastin time greater than 1.5 times normal
- Offer prothrombin complex concentrate to patients who are
taking warfarin and actively bleeding
- Treat patients who are taking warfarin and whose upper
gastrointestinal bleeding has stopped in line with local warfarin
protocols
Do not use recombinant factor Vlla except when all other methods
have failed

\section{Prophylactic antibiotics and vasoactive agents - variceal bleed}

In a meta-analysis with over 1000 patients with variceal UGIB, antibiotic prophylaxis had reduced mortality (RR $0.79,95 \% \mathrm{Cl}$ 0.63-0.98), and re-bleeding (RR 0.53,95\% Cl 0.38-0.74). Broad spectrum antibiotics e.g. cephalosporin or quinolone is usually administered..$^{19}$

Octreotide, somatostatin or terlipressin results in splanchnic vasoconstriction thus improving haemostasis. Somatostatin can be administered $250 \mathrm{mcg}$ IV bolus and then run at an infusion rate of $250 \mathrm{mcg} /$ hour over five days. ${ }^{20}$

\section{Prevention}

H. pylori infection, NSAIDs, smoking, and alcohol are the main areas where preventative strategies are necessary. Patients should be counselled on smoking cessation and limiting alcohol use as this impairs ulcer healing. Patients on long-term aspirin and other anti-platelets, NSAIDs and PPIs should be considered for $H$. pylori test and treat. If $H$. pylori is diagnosed, prompt eradication therapy with high dose PPI and dual antibiotics (amoxicillin and clarithromycin or metronidazole and clarithromycin if allergic to penicillin) for 14 days should be commenced. NSAIDs should be avoided if possible. In those patients where NSAIDs cannot be avoided, the best combination is a COX-2 inhibitor with a PPI.21,22

Aspirin therapy if used for secondary prevention in those with cardiovascular disease should be restarted as soon as the risk of cardiovascular disease outweighs the risk of bleeding (typically one to three days after endoscopic haemostasis). This should typically be low dose in combination with lifelong PPI to prevent bleeding recurrence. Long term PPI use carries an increased risk of hip fracture, pneumonia, possibly gastric cancer and Clostridium difficile infection. ${ }^{22,23}$

\section{Conclusion}

As family practitioners, we may be the first medical contact for a patient who presents with UGIB. Appropriate resuscitation based on risk stratification must be aimed at restoring haemodynamic stability and stopping the bleeding. Early endoscopic therapy within 24 hours is required for most patients. The GlasgowBlatchford score identifies a subset of patients suitable for outpatient management. Consideration on subsequent management following an UGIB should focus on prevention of re-bleeding.

\section{References}

1. Tang Y, Shen J, Zhang F, Zhou X, Tang Z, You T. Scoring systems used to predict mortality in patients with acute upper gastrointestinal bleeding in the ED. American Journal of Emergency Medicine; 2018;36:27-32. http://dx.doi. org/10.1016/j.ajem.2017.06.053

2. Upchurch BR. Upper gastrointestinal bleeding. Emedicine.medscape.com;2019, https://emedicine.medscape.com/article/187857-overview\#showall. [Accessed 13 August 2019].

3. Lu Y, Loffroy R, Lau JYW, Barkun A. Multidisciplinary management strategies for acute non-variceal upper gastrointestinal bleeding. BJS 2014;101:e34-e50. DOI: 10.1002/bjs.9351.

4. Button LA, Roberts SE, Evans PA, Goldacre MJ, Akbari A, et al. Aliment Pharmacol Ther 2011;33:64-76 doi:10.1111/j.1365-2036.2010.04495.x.

5. Feinmam M, Haut ER. Upper gastrointestinal bleeding. Surg Clin N Am;2014,94; 43 -53 http://dx.doi.org/10.1016/j.suc.2013.10.004

6. Saleem $\mathrm{S}$, Thomas AL. Management of upper gastrointestinal bleeding by an Internist. Cureus. 2018 Jun 25;10(6):e2878. doi: 10.7759/cureus.2878.

7. Flashcards Celiac Trunk (stomach blood supply) page 349 first aid. Quizlet. 2019. https://quizlet.com/248166301/flashcards [Accessed 30 July 2019].

8. Khamaysi I, Gralnek IM. Acute upper gastrointestinal bleeding (UGIB) - Initia evaluation and management. Best Pract Res Clin Gastroenterol. 2013;27(5):6338. doi: 10.1016/j.bpg.2013.09.002.

9. Thomson, SR. Approach to upper gastrointestinal bleeding. Continuing Medical Education, [S.I.], v. 31, n. 6, p. 213-217, jun. 2013. ISSN 2078-5143. Available at: <http://www.cmej.org.za/index.php/cmej/article/view/2784/3002>. [Accessed: 25 July 2019].

10. Longstreth GF. Epidemiology of hospitalization for acute upper gastrointestinal hemorrhage: a population-based study. The American Journal of Gastroenterology 1995;90(2):206-10.

11. Saltzman JR, Feldman M, Travis AC. Approach to acute upper gastrointestinal bleeding in adults. 2019 https://www.uptodate.com/contents/approach-toacute-upper-gastrointestinal-bleeding-in-adults [Accessed 30 July 2019].

12. Witting MD, Magder L, Heins AE, Mattu A, Granja CA, Baumgarten M. ED predictors of upper gastrointestinal tract bleeding in patients without hematemesis. The American Journal of Emergency Medicine. 2006;24(3):280-5.

13. Blatchford O, Murray WR, Blatchford M. A risk score to predict need for treatment for upper-gastrointestinal haemorrhage. Lancet 2000;356:1318-21.

14. Oakland K, Kahan BC, Guizzetti L, et al. Development, validation, and comparative assessment of an international scoring system to determine risk of upper gastrointestinal bleeding. Clin Gastroenterol Hepatol. 2019 May;17(6):1121-1129. e2. doi: 10.1016/j.cgh.2018.09.039. Epub 2018 Sep 27.

15. Srygley FD, Gerardo CJ, Tran T, Fischer DA. Does this patient have a severe upper gastrointestinal bleed? JAMA 2012;307(10):1072-9. doi: 10.1001/jama.2012.253.

16. Gralnek IM, Dumonceau JM, Kuipers EJ, Lanas A, Sanders DS, Kurien M, et al. Diagnosis and management of nonvariceal upper gastrointestinal hemorrhage: European Society of Gastrointestinal Endoscopy (ESGE) Guideline. Endoscopy. 2015;47(10):a1-46.

17. National Institute for Health and Care Excellence. Acute upper gastrointestinal bleeding in over 16s: management. Clinical Guideline [CG141]. 2016.

18. Jensen DM, Eklund $S$, Persson $T$, Ahlbom $H$, Stuart $R$, Barkun AN, et al. Reassessment of rebleeding risk of Forrest IB (oozing) peptic ulcer bleeding in a large international randomized trial. The American Journal of Gastroenterology. 2017;112(3):441-6.

19. Cheng HC, Wu CT, Chang WL, Cheng WC, Chen WY, Sheu BS. Double oral esomeprazole after a 3-day intravenous esomeprazole infusion reduces 
recurrent peptic ulcer bleeding in high-risk patients: a randomised controlled study. Gut. 2014;63(12):1864-72.

20. Chavez-Tapia NC, Barrientos-Gutierrez T, Tellez-Avila F, Soares-Weiser K, MendezSanchez N, Gluud C, et al. Meta-analysis: antibiotic prophylaxis for cirrhotic patients with upper gastrointestinal bleeding -an updated Cochrane review. Aliment Pharmacol Ther. 2011;34(5):509-18.

21. Garcia-Tsao G, Sanyal AJ, Grace ND, Carey W. Prevention and management of gastroesophageal varices and variceal hemorrhage in cirrhosis. Hepatology. 2007;46(3):922-38.

22. Gwee KA, Goh V, Lima G, Setia S. Coprescribing proton-pump inhibitors with nonsteroidal anti-inflammatory drugs: risks versus benefits. J Pain Res. 2018;11:361-374. doi:10.2147/JPR.S156938.

23. Åhsberg K, Höglund P, Kim W, von Holstein CS. Impact of aspirin, NSAIDs, warfarin, corticosteroids and SSRIs on the site and outcome of non-variceal upper and lower gastrointestinal bleeding. Scandinavian Journal of Gastroenterology. 2010, 45:12,1404-1415, DOI: 10.3109/00365521.2010.510567. 